\title{
Requirement for Increased IL-10 in the Development of B-1 Lymphoproliferative Disease in a Murine Model of CLL
}

\author{
Sumant Ramachandra, ${ }^{\star}$ Robert A. Metcalf, ${ }^{\ddagger}$ Torg Fredrickson, ${ }^{\ddagger}$ Gerald E. Marti, ${ }^{\ddagger}$ and Elizabeth Raveche ${ }^{\star}$ \\ *Department of Pathology, University of Medicine and Dentistry of New Jersey, Newark, New Jersey 07103; and ${ }^{\ddagger}$ Center for Biologics \\ Evaluation and Research, Food and Drug Administration, National Institutes of Health, Bethesda, Maryland 20812
}

\begin{abstract}
Malignant B-1 cells derived from NZB mice, a murine model of spontaneous autoimmunity and B cell lymphoproliferative disease, produce significantly higher levels of IL-10 mRNA than normal B-1 or B cells. IL-10 may act as an autocrine growth factor for the expansion of malignant B-1 cells. In order to determine if elevated endogenous production of IL-10 was a required element for the malignant transformation of B-1 cells in NZB mice, backcross animals were studied for the linkage between elevated IL-10 expression and the presence of lymphoid malignancy. The phenotypes of aged $(\mathrm{NZB} \times \mathrm{DBA} / 2) \mathrm{F}_{1} \times \mathrm{NZB}$ animals were determined and a strong correlation was found between the elevated levels of IL-10 mRNA and the development of B-1 malignant clones. In contrast, an increased level of IL-10 message was not associated with elevated serum IgM or the presence of anemia or reticulocytosis which is mainly seen in response to autoantibody production. These results indicate that, at least in NZB, the autoimmunity and lymphoproliferation phenotypes are not linked genetically. IL-10 may enhance proliferation and the development of B-1 cell malignancy rather than antibody production by the $B-1$ cell subpopulation. Thus, IL-10 plays an important role in B-1 malignancies, and downregulation of IL-10 could be a likely site for intervention in B cell malignancies. (J. Clin. Invest. 1996. 98:1788-1793.) Key words: IL-10 • B-1 cell • CD5+B cell • B-CLL • lymphoproliferation
\end{abstract}

\section{Introduction}

B-1 cells (CD5+B cells) have been found to be the malignant cell in a variety of lymphoproliferative diseases (LPD), particularly chronic lymphocytic leukemia (CLL) (1). Due to their long life span and capacity for self-renewal, B-1 cells may have a high potential to become malignant. We, as well as others, have described the expansion of B-1 clones and malignant transformation in aged New Zealand Black (NZB) $)^{1}$ mice (2-

Address correspondence to Dr. Elizabeth Raveche, University of Medicine and Dentistry of New Jersey, New Jersey Medical School, Department of Pathology, 185 South Orange Avenue, Newark, NJ 07103. Phone: 201-982-5240; FAX: 201-982-7293; E-mail: raveches@umdnj.edu

Received for publication 22 December 1996 and accepted in revised form 12 August 1996.

1. Abbreviations used in this paper: HPRT, hypoxanthine phosphoribosyl transferase; NZB, New Zealand Black; RT/PCR, reverse transcription-polymerase chain reaction.

The Journal of Clinical Investigation

Volume 98, Number 8, October, 1996, 1788-1793
4). Although NZB mice have been a classic model of autoimmune disease, due to their expansion of B-1 clones, NZB mice can also serve as a model for the study of human $B$ cell malignancies. Both malignant NZB B-1 cells and human B-CLL cells have been found to express IL-10 mRNA $(5,6)$. In vitro IL-10 antisense oligonucleotides were found to block cell growth in malignant NZB B-1 cells but had only minimal effect on non-malignant B-1 cell growth (5). Recently, IL-10 antisense was also found to cause growth retardation in human B-1 malignancies such as HIV-associated B-lymphoma cell lines (7) and CLL lines (8). IL-10 is a cytokine that can regulate the growth of B cells and particularly B-1 cells (9). B-1 cells are considered the main source of B cell derived IL-10 in the mouse (10). IL-10 not only functions as a potent growth and differentiation factor for activated human B lymphocytes, but has also been found to participate in the EBV transformation of human B cells as well as in the development of B cell lymphomas in AIDS patients $(11,12)$.

The increased frequency of CLL observed in patients with autoimmune disorders as well as the large proportion of autoreactivity in the CD5+ CLL cells producing IgM suggest a relationship between B-1 cells reacting with self-antigens and the emergence of a malignant clone. Extensive genetic analysis of the inheritance of autoimmune traits in NZB mice and their hybrids indicate that the autoimmune disease in NZB mice is dependent upon the action of several genes, some of which are linked (13-16). In the present study, the association of lymphoproliferative disease and autoimmune phenomenon was explored. In these experiments, $(\mathrm{NZB} \times \mathrm{DBA} / 2) \mathrm{F}_{1} \times \mathrm{NZB}$ animals were employed because individual backcross mice inherit independently any combination of parental genes. Analysis of backcross animals can provide estimations of the linkage between traits observed in the inbred NZB parent because every backcross animal is somewhat unique in the proportion of either parental genotype which is inherited. Thus, study of backcross animals allows for an analysis of a possible correlation between the levels of IL-10 mRNA and the presence of lymphoproliferative disease in the spleen.

\section{Methods}

Mice. NZB and DBA/2 mice were obtained from Jackson Laboratory (Bar Harbor, ME). (NZB $\times \mathrm{DBA} / 2) \mathrm{F}_{1}$ animals as well as $\mathrm{F}_{1} \times$ NZB backcross animals were bred at the Animal Facilities (Center for Biologics Evaluation and Research, Food and Drug Administration). Backcross animals were studied at $>12$ mo old.

Blood and tissue. The blood was collected by cardiac puncture in EDTA and analyzed for WBC, RBC, platelet count, white cell differential, percent reticulocytes and serum IgM by Anilytics, Inc. (Gaithersburg, MD). The spleens were excised, weighed, and samples were taken for histology, RNA, and DNA.

Flow cytometry. Cells $\left(1 \times 10^{6}\right)$ were stained with the following reagents: FITC conjugated goat anti-IgM, anti-Ly1.2-PE (anti-CD5) 
and anti-B220-TriColor PE-Cy5 for three-color analysis (Caltag Labs, San Francisco, CA) and analyzed on a flow cytometer (model FACScan; Becton Dickinson, Sunnyvale, CA). Appropriately labeled isotype controls were employed to determine background values. For cell cycle analysis, cell suspensions were fixed in ethanol, stained with propidium iodide (PI, $50 \mu \mathrm{g} / \mathrm{ml}$; Calbiochem Corp., San Diego, CA) and ribonuclease $(1 \mathrm{mg} / \mathrm{ml}$, Sigma Chemical Co., St. Louis, MO). CELLFIT software was used for acquisition and analysis $(20,000$ events). Aneuploid clones were detected by the presence of a second hyperdiploid G1 peak constituting greater than $5 \%$ of the diploid G1 peak.

Detection of IL-10 protein. IL-10 protein in serum and culture supernatants was detected by ELISA (mouse IL-10 ultrasensitive detection system at a range of 0.25 to $80 \mathrm{pg} / \mathrm{ml}$ ) as per the manufacturer's protocol (Biosource International, Camarillo, CA).

PCR of cytokine message. Total RNA was obtained with Trizol (GIBCO BRL, Gaithersburg, MD). First strand synthesis was accomplished using Superscript II Reverse Transcriptase (GIBCO BRL) and PCR was performed with the GeneAmp DNA PCR kit (PerkinElmer Corp., Norwalk, CT). All primers were synthesized by Operon Technols., Inc. (Alameda, CA). IL-10 and HPRT primers and amplification conditions employed have previously been described (5). The amplification was performed for 30 cycles which was shown to be in the linear range. Analysis of densitometric images of ethidium bromide (EB) stained gels were performed using ImageQuant software (Molecular Dynamics, Inc., Sunnyvale, CA). Relative IL-10 PCR values were normalized for the amount of HPRT PCR product to allow comparisons between samples.

Statistical analysis. Data was imported from the EXCEL (Microsoft, San Francisco, CA) spreadsheet into statistical software program (SAS Institute, Cory, NC). Pearson correlation analysis was performed for the selected variables for all 60 backcross animals.

\section{Results}

Analysis of backcross animals. Previous analysis had demonstrated that NZB mice at $1 \mathrm{yr}$ develop enlarged spleens, elevated IL-10 production, increased numbers of CD45/B220 dull B-1 cells, and lymphoproliferative disease (LPD) $(2,17)$. In addition to these abnormalities, NZB mice at $1 \mathrm{yr}$ have hypergammaglobulinemia $\mathrm{M}$, and the presence of autoantibodies directed at nuclear antigens and red blood cells (16). The antierythrocyte antibodies lead to anemia, elevated reticulocytes, and contribute in part to the increased spleen size. The DBA/2 strain, on the other hand, shows none of these abnormalities at $1 \mathrm{yr}$ (16). F1 crosses between these two strains were backcrossed to NZB mice as part of a linkage study to determine the numbers and locations of genes controlling the various components of the NZB lymphoproliferative disorder. The first 60 backcross animals were analyzed for several traits which may be related to the lymphoproliferative disease (Table I). One-third of the animals had spleen weights greater than $300 \mathrm{mg}$. The spleen weight values for the two parental

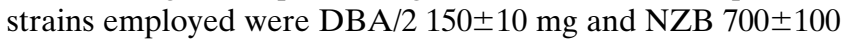
$\mathrm{mg}$ (18). The F1 mice from this cross also had normal spleen weights of $115 \pm 15 \mathrm{mg}$. Nearly half of the backcross animals had evidence of B-1 clonal expansions at the time of study and most of these $(81 \%)$ were B-1a clones $\left(\operatorname{IgM}^{+}, \mathrm{CD}^{+}\right)$. Over a third of the animals had serum IgM levels greater than $600 \mathrm{mg} /$ liter. The NZB and DBA/2 parental strains had serum IgM levels of $950 \pm 50$ and $360 \pm 50 \mathrm{mg} /$ liter, respectively (19).

Half of the backcross animals had increased IL-10 mRNA ratios. The IL-10/HPRT RNA PCR product ratios for $1 \mathrm{yr}$ NZB spleen cells was over a 100-fold greater than that of $1 \mathrm{yr}$ DBA/2 spleen cells, with the DBA/2 IL-10 levels being close to
Table I. Abnormal Traits in the Backcross Mice

\begin{tabular}{lcc}
\hline \multicolumn{1}{c}{ Trait } & No. with trait/total & $\%$ \\
\hline Splenomegaly & $20 / 59$ & 34 \\
B-1 clone & $27 / 58$ & 47 \\
Elevated serum IgM $^{\mathrm{b}}$ & $22 / 60$ & 37 \\
Increased IL-10 mRNA $^{\mathrm{c}}$ & $31 / 60$ & 52
\end{tabular}

${ }^{\text {a }}$ Splenomegaly was defined as spleen weight $\geq 300 \mathrm{mg} .{ }^{\mathrm{b}}$ Serum $\mathrm{IgM}$ was considered elevated when it was $\geq 600 \mathrm{mg} / \mathrm{dl}$. ${ }^{\mathrm{c}} \mathrm{IL}-10$ expression was considered increased when the ratio of amplified IL-10 to HPRT was $\geq 0.3$.

undetectable (IL-10/HPRT ratios between 0.008 and 0.002) (20). In the spleen of old NZB mice there is an expansion of B-1 clones, this suggests that in malignant B-1 cells there is increased autocrine production of IL-10 message and protein. This fact has been verified by analysis of purified NZB malignant B-1 cells which have normalized IL-10/HPRT PCR product ratio several thousand-fold higher than normal purified $\mathrm{B}$ cells (20). Serum levels of IL-10, measured by a murine IL-10 ELISA (Biosource International, Camarillo, CA), from old NZB mice, which had elevated B-1 cells, was $17.7 \mathrm{pg} / \mathrm{ml}$. In contrast, DBA/2 mice did not have detectable serum IL-10. Likewise IL-10 levels in culture supernatants of control malignant B-1 cells and those treated with antisense IL-10 was 31.6 versus $4.1 \mathrm{U} / \mathrm{ml}$, respectively (5). Lysed (hypotonic) malignant B-1 cells had even higher IL-10 protein (personal observation) further suggesting that IL-10 acts in an autocrine manner. In addition, antisense IL-10 was shown to induce apoptosis thus supporting the pivotal role of IL-10 in B-1 cell expansion (5).

57 backcross animal's spleens were analyzed histologically (Table II). Lymphoproliferative disease, defined as a histological loss of splenic architecture, was present in $18 \%$ of backcross animals. However, $91 \%$ of the backcross animals had abnormal spleen histology. In the majority of cases there was an enlarged red pulp, and this was correlated with reticulocytosis and anemia. In others, the white pulp area was increased (reactive) but no evidence of overt lymphoproliferative disease was evident. In other cases, the spleen was increased in both red and white pulp areas suggesting both increased erythropoiesis and a reactive lymphopoiesis was occurring.

Of the animals determined to have lymphoproliferative disease (10/57), analysis of traits revealed that histological diagnosis correlated with the expression of other lymphoid abnormalities (Table III). Splenomegaly was seen in a majority of the backcross animals with LPD, however, spleens displaying early marginal-zone lymphomas had the least amount of splenomegaly. Only two backcross animals with LPD did not have increased IL-10 mRNA, both of these animals possessed

Table II. Spleen Histology in the Backcross Mice

\begin{tabular}{lcr}
\hline \multicolumn{1}{c}{ Spleen histology } & No. positive/total & $\%$ \\
\hline Normal & $5 / 57$ & 9 \\
Enlarged red pulp & $21 / 57$ & 37 \\
Enlarged white pulp & $11 / 57$ & 19 \\
Enlarged red and white pulp & $10 / 57$ & 18 \\
Lymphoproliferative disease & $10 / 57$ & 18
\end{tabular}


Table III. Backcross Mice with Lymphoproliferative Disease and the Presence of Abnormal Traits

\begin{tabular}{lccccc}
\hline LPD $^{\mathrm{a}}$ & Splenomegaly $^{\mathrm{b}}$ & $\begin{array}{c}\text { Increased } \\
\text { IL-10 }^{\mathrm{c}}\end{array}$ & $\begin{array}{c}\text { Increased } \\
\text { B-1 cells }\end{array}$ & $\begin{array}{c}\text { B-1 } \\
\text { Clones }^{\mathrm{d}}\end{array}$ & $\begin{array}{c}\text { Aneuploidy } \\
\text { (Hyperdiploidy) }^{\mathrm{e}}\end{array}$ \\
\hline EMZL & - & + & + & - & + \\
EMZL & - & + & + & - & - \\
EMZL & + & ++ & + & + & + \\
MZL & ++ & ++ & + & + & + \\
CBL & ++ & ++ & + & + & + \\
LBL & ++ & ++ & + & + & - \\
UPC & ++ & + & + & + & - \\
PC & ++ & ++ & + & + & + \\
PC & - & - & + & - & - \\
PC & - & - & + & + & - \\
& & & & & + \\
\hline
\end{tabular}

${ }^{a}$ LPD is a histopathological diagnosis of early marginal-zone lymphoma (EMZL), marginal-zone lymphoma (MZL), centroblastic lymphoma (CBL), lymphoblastic lymphoma (LBL), undifferentiated plasmacytoma (UPC), plasmacytoma (PC). ${ }^{\text {b } S p l e n o m e g a l y ~ w a s ~ d e f i n e d ~ a s ~ s p l e e n ~}$ weight $\geq 300 \mathrm{mg}$. (+) signifies spleens $\geq 300 \mathrm{mg}$ and $<700 \mathrm{mg}$. (++) signifies spleens $\geq 700 \mathrm{mg}$. ${ }^{c}$ IL-10 expression was considered increased when the ratio of amplified IL-10 to HPRT was $\geq 0.3$. (+) signifies a ratio $\geq 0.3$ and $<0.75$. $(++)$ signifies a ratio $\geq 0.75$. ${ }^{\text {d}}$ Presence of B- 1 cells clones were determined by flow-cytometric analysis of whole spleen cells for $\mathrm{IgM}^{+} / \mathrm{CD}^{+} / \mathrm{B} 220(6 \mathrm{~B} 2)^{\text {dull- }}$ (B-1 a cells) and for $\mathrm{IgM}^{+} / \mathrm{CD}^{-} /$ B220(6B2) $)^{\text {dull/- }}$ (B-1b cells). ${ }^{\mathrm{e}}$ Aneuploidy (hyperdiploidy) was determined by flow cytometric DNA analysis of PI stained cells for a second $>2 \mathrm{~N} \mathrm{G}_{1}$ peak. a plasmacytoma as the predominant clone. Aneuploidy was not a consistent feature in aged NZB mice (18). Similarly, not all the malignant clones in the backcross animals were aneuploid, although there is a significant association $(P=0.05)$ of lymphoproliferative disease and aneuploidy.

Correlation of traits in backcross animals. The degree of correlation between IL-10 and the several phenotypic end points associated with lymphoproliferative disease was determined. Correlation analysis was performed on the values for the traits obtained for each backcross animal (Fig. 1). This type of analysis allows a determination of correlation between the appearance of two traits by the derivation of an $R$ value with significant values indicated. Elevated levels of IL-10 strongly correlated with the development of lymphoproliferative disease $(P<0.05)$. Because the lymphoproliferative disease in NZB mice is due to expansion of malignant B-1 cells, it is not surprising that there was also significant correlation between the levels of IL-10 and the presence of hyperdiploid B-1 clones. The correlation of IL-10 levels with proportion of B-1 cells and WBC count was less dramatic than was the correlation of IL-10 with clonal B-1 expansion and hyperdiploidy. This suggests that factors other than IL-10 allow for B-1 cell growth while IL-10 is required for the development B-1 clones. In contrast, the levels of IL-10 were not correlated with serum IgM or the decrease in red blood cells both of which are related to the autoimmune disease occurring in NZB mice. As would be expected, the decrease in erythrocytes was associated with an absolute reticulocytosis (Pearsons correlation,

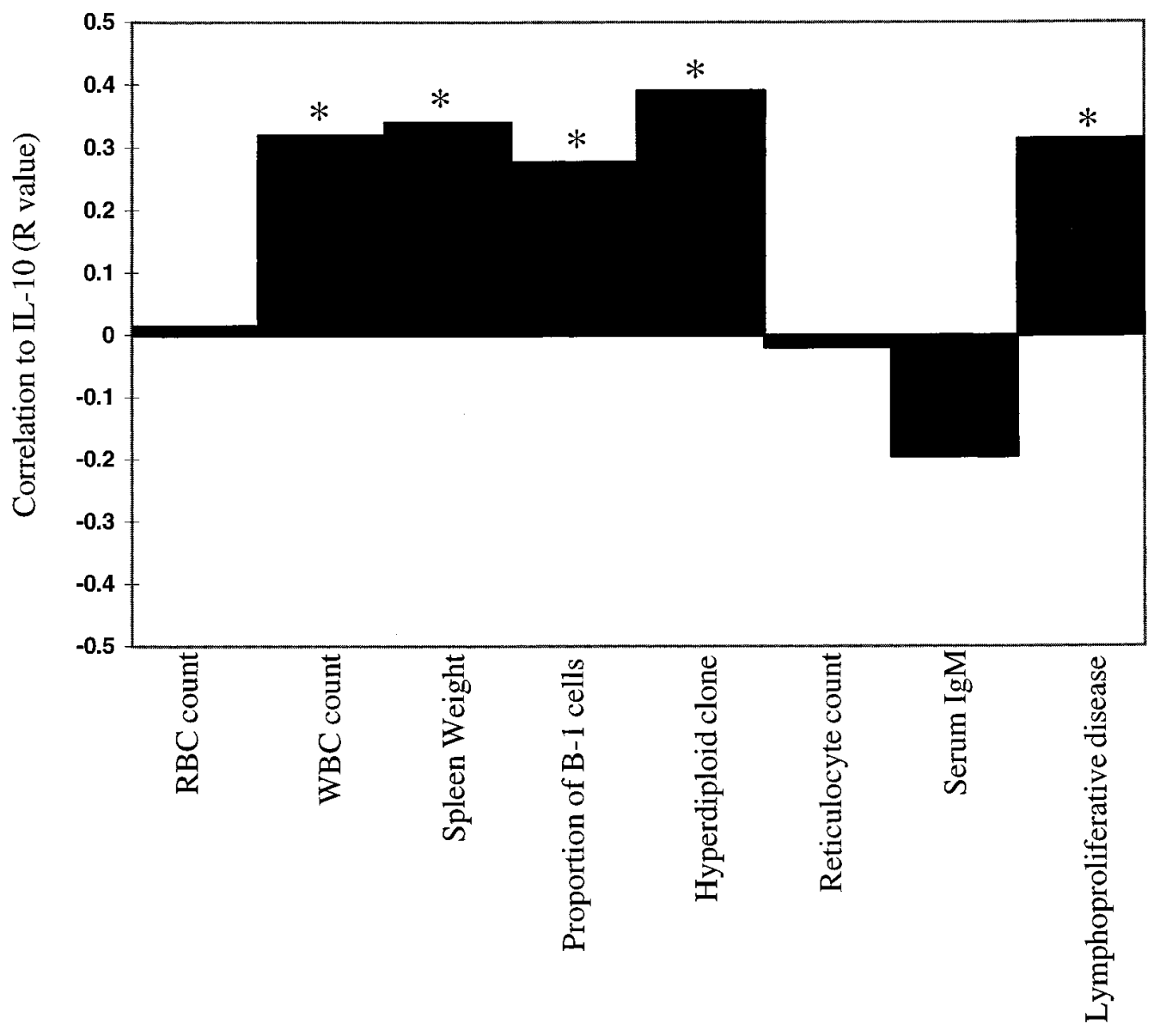

Figure 1. Correlation of IL-10 with NZB disease traits. Correlation coefficients ( $\mathrm{R}$ values) were determined by Pearson's correlation analysis for IL-10 mRNA levels and several traits measured in $(\mathrm{NZB} \times \mathrm{DBA} / 2) \mathrm{F} 1 \times$ NZB backcross animals. All traits are continuous variables as described in Methods except for the presence of hyperdiploid clones and lymphoproliferative disease which were binary. The proportion of B-1 cells was determined by flow cytometric analysis of $\operatorname{IgM}+, \mathrm{CD} 5+$ cells in the total spleen. 60 backcross animals between ages 20-24 mo were studied. $R$ values which indicate significant positive correlation are indicated by an asterisk $(P<0.05)$. 

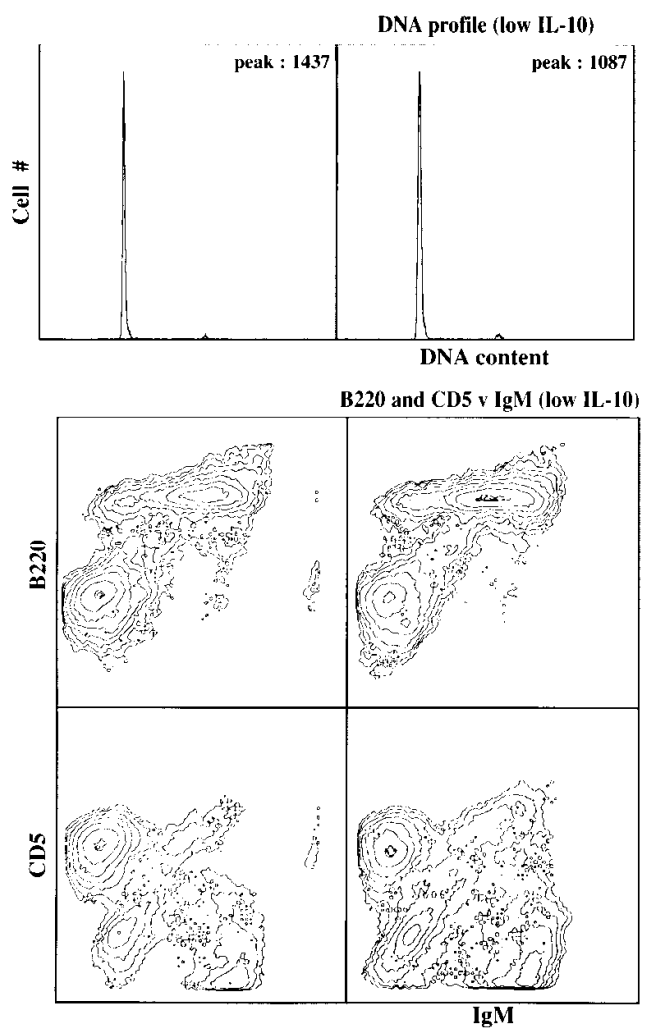
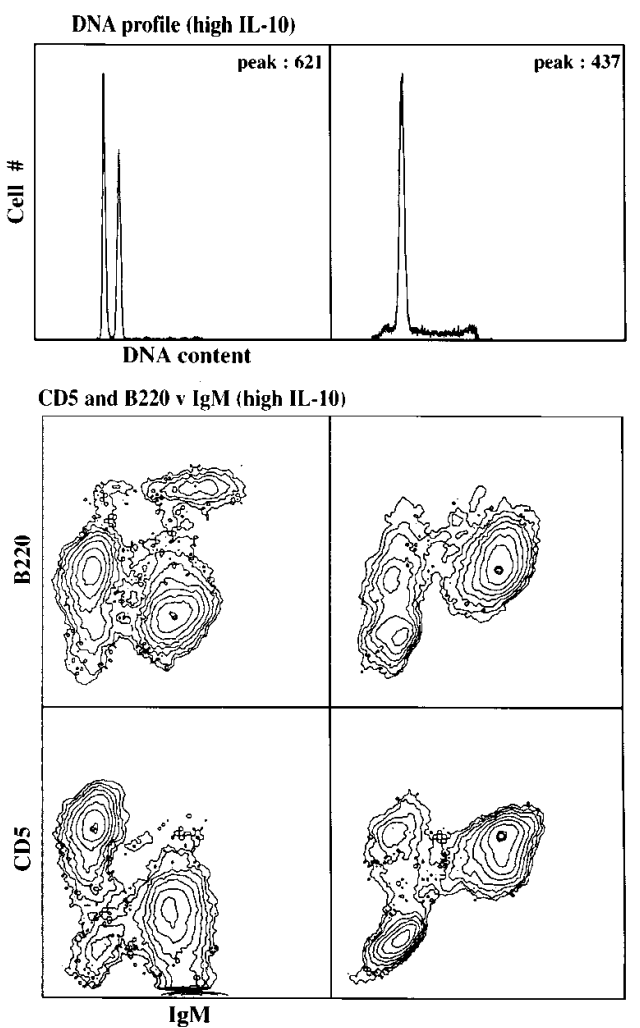

Figure 2. Flow cytometric analysis. The histograms are divided into two groups based upon the IL-10/HPRT RT-PCR product ratios of the backcross spleens. (Left) Two representative animals with low IL-10 mRNA (IL-10/HPRT < 0.20). (Right) Two representative animals with high IL-10 mRNA (IL-10/HPRT > 0.75). (Top row) Cells stained for DNA content with PI (second G1 peak = hyperdiploid). (Middle row) IgM FITC and B220 TriColor PECy5. (Bottom row) IgM FITC and CD5 PE. Malignant B-1 clones (right panels) are $\mathrm{IgM}+$ but have reduced CD45/B220 expression and are $\mathrm{CD}^{+}$.
$P<0.0001$, and data not shown). These results indicate that increased levels of IL-10 are a requirement for the development of lymphoproliferative disease in the murine model.

Representative findings in backcross animals separated according to IL-10 mRNA expression levels. The (NZB $\times$ $\mathrm{DBA} / 2) \mathrm{F}_{1} \times \mathrm{NZB}$ animals were separated into two distinct groups based on the relative amounts of IL-10. Those animals with high densitometric values for IL-10 relative to values for HPRT PCR products were considered high IL-10 (IL-10/ HPRT > 0.75), those animals with low IL-10 had IL-10/HPRT ratios $<0.20$. Representative examples of flow cytometric analysis of DNA and surface markers (Fig. 2), and PCR products (Fig. 3) for backcross animals are shown. Differences be- tween the high and low IL-10 groups are clear. The backcross animals that had low levels of normalized IL-10 did not have an expansion of B-1 cells or hyperdiploid cells (Fig. 2) or splenic pathology indicative of malignancy. In contrast, the backcross animals with high IL-10 levels exhibited increased clonality of B-1 cells with decreased levels of B220 expression. The reduced amount of the B cell isoform of B220 may, in part, be responsible for abnormal signaling in the malignant B-1 cells (21). Two splenic histopathologic findings are demonstrated in Fig. 4. These spleen sections are from the same mice presented in Fig. 2 which had elevated IL-10 levels and the presence of B-1 clones with reduced B220 expression. Both representative animals demonstrated lymphoproliferative dis-

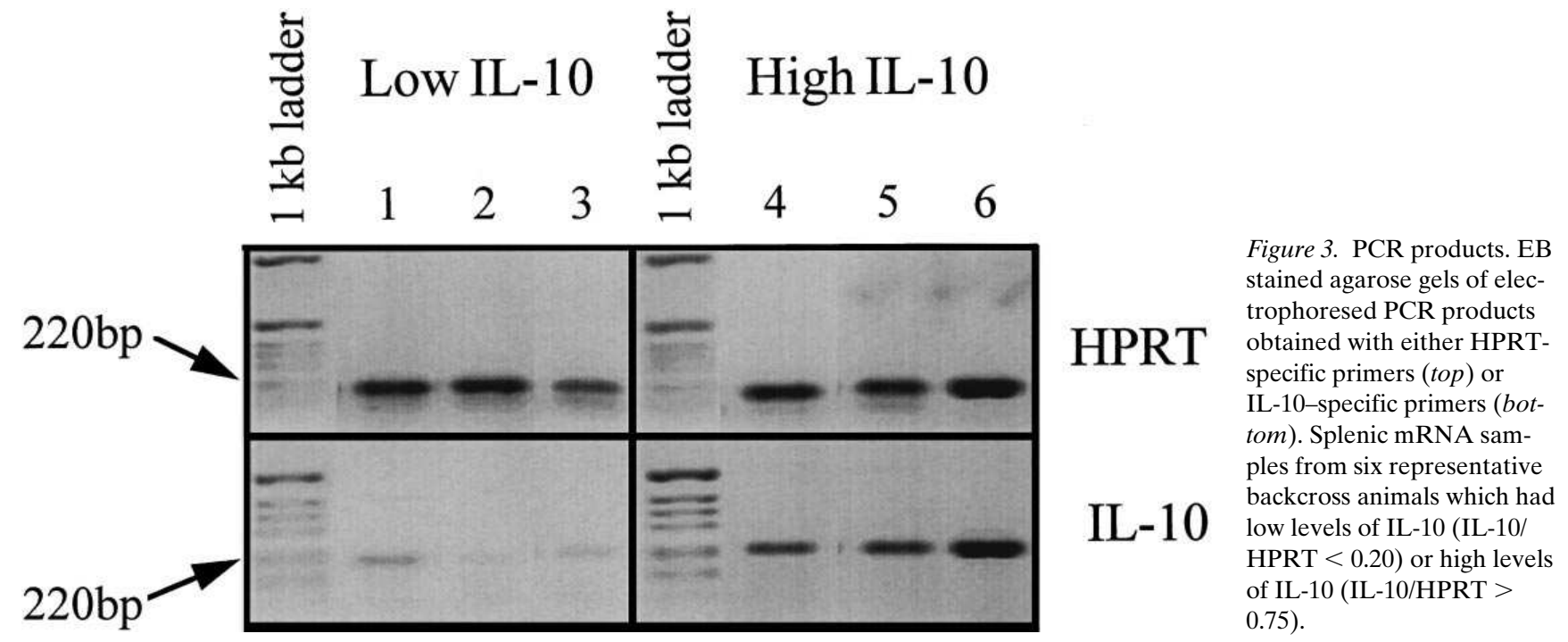




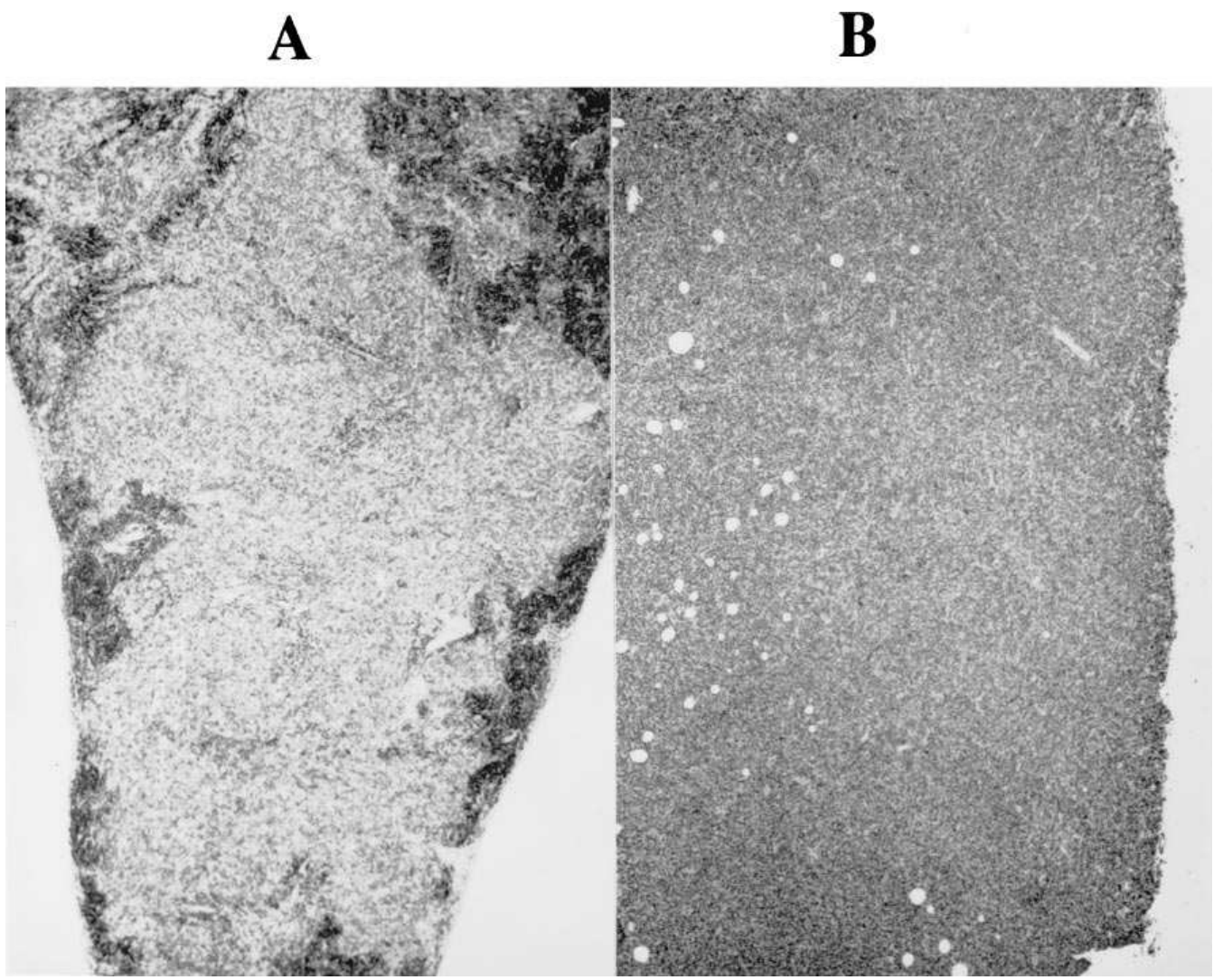

Figure 4. Spleen histology. $\mathrm{H} \&$ E stained spleen sections from $\mathrm{F} 1 \times$ NZB backcross animals expressing high levels of IL-10 and abnormal spleen histology $(\times 40) .(A)$ Marginal zone lymphoma, and $(B)$ undifferentiated plasmacytoma. ease. The spleen from the first animal shows a marginal zone cell lymphoma (Fig. $4 A$ ) and the spleen of the second animal is totally replaced by an undifferentiated plasmacytoma (Fig. 4 $B)$. These results demonstrate that the B-1 lymphoproliferation observed in the NZB backcross animals can have differing histopathology in individual animals yet still be associated with elevated IL-10 levels.

\section{Discussion}

The present study suggests that there is a strong correlation between the presence of high levels of IL-10 and the development of B-1 malignancies in NZB hybrids. Previous reports have shown that IL-10 is an autocrine B cell growth factor for human B cell lymphomas (7). Elevated serum IL-10 has been found in patients with diffuse large cell lymphoma (22) but the presence of serum IL-10 in patients with CLL is varied (23). The failure to detect serum levels of IL-10 in some CLL patients may reflect the fact that IL-10 is produced in an autocrine manner by the malignant B-1 cells. Masood et al. (7) showed that human IL-10 acted as an autocrine growth factor for AIDS-related B cell lymphomas. Many of these lymphomas have been shown to be comprised of CD5+ B cells (24, $25)$. We as well as others have reported that IL-10 mRNA levels can also be varied in CLL $(6,8,26)$. However, the NZB mouse, the murine model of CLL, has consistently elevated serum IL-10 levels and increased IL-10 mRNA expression in the malignant B-1 cells. Both human and murine malignant B-1 cell growth can be blocked by IL-10 antisense oligonucleotides $(5,7,8)$. Results from the current backcross studies also demonstrate the requirement for IL-10 in the development of B cell malignancies in NZB hybrids. Elevated IL-10 mRNA ex- pression observed in individual NZB backcross mice was linked to the presence of lymphoproliferative disease.

In both the NZB murine model and in patients with B-CLL, autoantibodies, particularly anti-erythrocyte antibodies which result in hemolytic anemia in some CLL patients, are produced mainly due to secretion by B-1 cells. In the current experiments, there is a lack of correlation between elevated IL-10 levels and hyper-IgM production or anemia. This suggests that abnormalities in NZB mice which result in autoantibody production may not be dependent upon IL-10 levels or correlated to the presence of lymphoproliferative disease. While exogenous IL-10 has been shown to decrease experimental autoimmune thyroiditis by downregulating CTL responses (27), antiIL-10 administration to autoimmune NZB/NZW mice (an autoimmune disease characterized by $\mathrm{IgG}$ rather than IgM autoantibodies) resulted in increased survival (28). Thus, depending upon the type of autoimmune disease involved, IL-10 can have an upregulatory or downregulatory effect. Although studies have shown that IL-10 is capable of inducing CD-40 activated normal human B cells and B-CLL cells to proliferate and differentiate into Ig-secreting cells (9), very high levels of endogenous B-1 cell production of IL-10 may bypass the requirement for $\mathrm{T}$ cell activation and lead to clonal expansion rather than Ig production. Recent studies have suggested that high levels of IL-10 will inhibit the ability of CLL B cells to interact with T cells (29). Thus, proliferation and immunoglobulin secretion are mutually exclusive and it now appears that a B cell-specific activator protein (BSAP) favors B cell proliferation while having a negative effect on $B$ cell secretion of immunoglobulin (30). Thus, in NZB mice and their hybrids, B-1 cells may be responsible for some types of autoantibody production but these B-1 cells are not necessarily malignant and may not 
require high levels of IL-10. In fact, there is a negative correlation between hyper IgM observed in aging NZB mice and elevated IL-10 levels. This suggests that B-1 malignant cells which proliferate into a clone are not involved in the differentiated function of autoantibody production. In contrast, the development of a malignant B-1 clone may be dependent upon the presence of high levels of IL-10. The stimulus which results in high autocrine production of IL-10 is as yet unknown.

Some studies state that IL-10 knockout mice have normal B-1 cell subsets in the spleen and peritoneum suggesting that IL-10 is not an absolute requirement for B-1 cell development (31). In the present studies, we have found elevated IL-10 in those backcross animals in which lymphoproliferative disease, involving B-1 clones, is present. This might indicate that although IL-10 is not required for normal B-1 cell development, it may be necessary for, or predisposed to, uncontrolled growth and malignant transformation of B-1 cells. IL-10 has been found to enhance proliferation and antibody production of B cells activated by CD40, but does not allow for long-term survival of non-malignant B cells (32). In contrast to the situation seen in normal B cells, IL-10 may be responsible for malignant B cell survival because these cells have high levels of IL-10. Studies by others of in vitro and in vivo expression of IL-10 mRNA showed it to be elevated in transplantable murine $\mathrm{B}$ lymphocyte malignancies despite difference in the stage of B cell differentiation (33). The IL-10 produced may enhance the ability of the malignant $\mathrm{B}$ cell to inhibit antitumor responses, particularly those by Th1 cells. However, since in vitro growth of malignant B-1 cells is inhibited by antisense IL-10 $(6,8)$, and the backcross mice generated in this study had elevated IL-10 linked to the development of lymphoproliferative disease, these studies indicate IL-10 is required for the growth of the malignant B-1 cells as well as for escape from immune surveillance. IL-10 may act as a transcriptional regulator of genes involved in transformation, and IFN- $\gamma$ may inhibit this activation which may explain findings of IFN- $\gamma$ downregulation of CLL growth (34). Therefore, the finding of a correlation in NZB backcross animals between the levels of IL-10 and B-1 clonal development and lymphoproliferative disease support the concept that IL-10 is a required component in many B-1 malignancies.

\section{Acknowledgments}

This study was supported in part by NIH grant CA-71478.

\section{References}

1. Rozman, C., and E. Montserrat. 1995. Chronic lymphocytic leukemia. $N$. Engl. J. Med. 333:1052-1057.

2. Phillips, J., K. Mehta, C. Fernandez, and E. Raveche. 1992. The NZB mouse as a model for CLL. Cancer Res. 52:437-443.

3. Stall, A., M. Farinas, D. Tarlinton, P. Lalor, L. Herzenberg, S. Strober, and L. Herzenberg. 1988. Ly-1 B cell clones similar to human CLL routinely develop in older normal mice and young autoimmune NZB related animals. Proc. Natl. Acad. Sci. USA. 85:7312-7316.

4. Okamoto, H., H. Nishimura, A. Shinozaki, D. Zhang, S. Hirose, and T. Shirai. 1993. H-2z homozygous New Zealand mice as a model for B cell chronic lymhocytic leukemia: elevated bcl-2 expression in CD5 B cells at premalignant and malignant stages. Jpn. J. Cancer Res. 84:1273.

5. Peng, B., N. Mehta, H. Fernandes, C. Chou, and E. Raveche. 1995. Growth inhibition of malignant CD5+B (B-1) cells by antisense IL-10 oligonucleotide. Leuk. Res. 19:159-167.

6. Finke, J., P. Ternes, W. Lange, R. Mertelsmann, and G. Dolken. 1993. Expression of IL-10 in B lymphocytes of different origin. Leukemia (Baltimore). 7:1852-1857.
7. Masood, R., Y. Zhang, M. Bond, D. T. Scadden, T. Moudgil, R. Law, M. Kaplan, B. Jung, B. Espina, Y. Lunardi-Iskandar, et al. 1995. IL-10 is an autocrine growth factor for acquired immunodeficiency syndrome-related B cell lymphoma. Blood. 85:3423-3430.

8. Fernandes, H., W. Barchuk, S. Ramachandra, C. Chou, G. Fernandes, and E. Raveche. 1995. Regulation of CLL by IL-10: Role of antisense IL-10. Oncol. Rep. 2:985-989.

9. Fluckiger, A., P. Garrone, I. Durand, J. Galizzi, and J. Banchereau. 1993. IL-10 upregulates functional high affinity IL-2 receptors on normal and leukemic B lymphocytes. J. Exp. Med. 178:1473-1481.

10. O'Garra, A., R. Chang, N. Go, R. Hastings, G. Haughton, and M. Howard. 1992. Ly-1 B (B-1) cells are the main source of B cell-derived interleukin 10. Eur. J. Immunol. 22:711-717.

11. Benjamin, D., T.J. Knobloch, and M.A. Dayton. 1992. Human B-cell interleukin-10: B-cell lines derived from patients with acquired immunodeficiency syndrome and Burkitt's lymphoma constitutively secrete large quantities of interleukin-10. Blood. 80:1289-1298.

12. Miyazaki, I., R.K. Cheung, and H.M. Dosch. 1993. Viral interleukin 10 is critical for the induction of B cell growth transformation by Epstein-Barr virus. J. Exp. Med. 178:439-447.

13. Morel, L., U. Rudofsky, J. Longmate, J. Schiffenbauer, and E. Wakeland. 1994. Polygenic control of susceptibility to murine systemic lupus erythematosus. Immunity. 1:219-229.

14. Kono, D., R. Burlingame, D. Owens, A. Kuramochi, R. Balderas, D. Balomenos, and A. N. Theofilopoulos. 1994. Lupus susceptibility loci in New Zealand mice. Proc. Natl. Acad. Sci. USA. 91:10168-10172.

15. Drake, C., S. Rozzo, H. Hirschfeld, N. Smarnworaworg, F. Palmer, and B. Kotzin. 1995. Analysis of the NZB contribution to lupus-like renal disease. Multiple genes that operate in a threshold manner. J. Immunol. 154:2441-2447.

16. Raveche, E., E. Novotny, C. Hansen, J. Tjio, and A. Steinberg. 1981. Genetic studies in NZB mice V. Recombinant inbred lines demonstate that separate genes control autoimmune phenotype. J. Exp. Med. 153:1187-1197.

17. Raveche, E., J. Phillips, F. Mahboudi, A. Dang, H. Fernandes, S. Ramachandra, T. Lin, and B. Peng. 1992. Regulatory aspects of clonally expanded B-1 cells. Int. J. Clin. Lab. Res. 22:220-234.

18. Raveche, E.S., J.H. Tjio, and A.D. Steinberg. 1979. Genetic studies in NZB mice II. Hyperdiploidy in the spleen of NZB and their hybrids. Cytogenet. Cell Genet. 23:182-193.

19. Raveche, E.S., A.D. Steinberg, L.W. Klassen, and J.H. Tjio. 1978. Genetic studies in NZB mice. I Spontaneous autoantibody production. J. Exp. Med. 147:1487-1502.

20. Peng, B., D.H. Sherr, F. Mahboudi, J. Hardin, L. Sharer, and E.S Raveche. 1994. A cultured malignant B-1 line serves as a model for Richter's syndrome. J. Immunol. 19:159-167.

21. Dang, A., M. Balasubramanyam, Z. Garcia, J. Gardner, and E. Raveche. 1995. Altered calcium signal transduction in B-1 malignant cells. Immunol. Cell Biol. 73:511-520.

22. Cortes, J.E., M. Talpaz, F. Cabanillas, J.F. Seymour, and R. Kurzrock. 1995. Serum levels of IL-10 in patients with diffuse large cell lymphoma: Lack of correlation with prognosis. Blood. 85:2516-2520.

23. Knauf, W., B. Ehlers, S. Bisson, and E. Thiel. 1995. Serum levels of IL-10 in B-CLL. Blood. 86:4382-4386.

24. Mercolino, T., B. Herndier, T. Nolan, and M. McGrath. 1992. Large cell "mixed phenotype" lymphoma in AIDS. Ann. NY Acad. Sci. 651:409-421.

25. Ng, V.L., M.H. Hurt, B.G. Herndier, and M.S. McGrath. 1995. VH gene use by CD5+ AIDS-associated B-cell lymphoproliferations. Ann. NY Acad. Sci. 764:507-508.

26. Sjoberg, J., M. Aguilar-Santelises, A.M. Sjogren, E.K. Pisa, A. Ljundgdahl, M. Bjorkholm, M. Jondal, H. Mellstedt, and P. Pisa. 1996. IL-10 mRNA expression in B-CLL inversely correlates with progression of disease. Br. J. Haematol. 92:393-400.

27. Mignon-Godefroy, K., O. Rott, M. Brazillet, and J. Charreire. 1995. Curative and protective effects of IL-10 in experimental autoimmune thryroiditis. J. Immunol. 154:6634-6643.

28. Ishida, H., T. Muchamuel, S. Sakaguchi, S. Andrade, S. Menon, and M. Howard. 1994. Continuous administration of anti-IL-10 antibodies delays onset of autoimmunity in NZB/W F1 mice. J. Exp. Med. 179:305-310.

29. Ranheim, E.A., M.J. Cantwell, and T.J. Kipps. 1995. Expression of CD27 and its ligand, CD70, on CLL B cells. Blood. 85:3556-3565.

30. Neurath, M.F., E.R. Stuber, and W. Strober. 1995. BSAP: a key regulator of B cell development and differentiation. Immunol. Today. 16:564-569.

31. Kuhn, R., J. Lohler, D. Rennick, K. Rajewsky, and W. Muller. 1993. IL-10 deficient mice develop chronic enterocolitis. Cell. 75:263-274.

32. Rousset, F., E. Garcia, T. Defrance, C. Peronne, N. Vezzio, D.H. Hsu, R. Kastelein, K.W. Moore, and J. Banchereau. 1992. Interleukin 10 is a potent growth and differentiation factor for activated human B lymphocytes. Proc. Natl. Acad. Sci. USA. 89:1890-1893.

33. Bost, K.L., S.C. Bieligk, and B.M. Jaffe. 1995. Lymphokine mRNA expression by transplantable murine B lymphocytic malignancies. J. Immunol. 154:718-729.

34. Panayiotidis, P., K. Ganeshaguru, L. Foroni, and A. Hoffbrand. 1995. Expression and function of fas antigen in B-CLL and Hairy cell leukemia. Leukemia (Baltimore). 9:1227-1232. 